\title{
Magnetic Resonance Imaging in sonographically indeterminate adnexal masses
}

\author{
Salam M. Joori*, \\ Atheer A. Fadhil** \\ Wassen M. Abdullateef,* \\ Maysoon M. Jabir***
}

\author{
DMRD, FJMC \\ DMRD, FIBMS \\ MBChB \\ CABGO
}

\begin{abstract}
:
Background: Although ultrasonography (US) continues to be the primary imaging modality used to identify and characterize adnexal masses, but certain conditions that hinder accurate ultrasound examination, such as obesity, may be indications for magnetic resonance (MR) imaging, for the assessment of complex and indeterminate ovarian masses.

Fac Med Baghdad 2015; Vol.57, No.4 Received: June,2015 Accepted: Oct,2015

Objective: to assess the ability of MRI to characterize sonographically indeterminate adnexal masses.

Patients and methods: A prospective study of 89 cases with sonographically indeterminate adnexal mass underwent pelvic MRI conducted in X-ray institute in medical city in Baghdad during period from October 2011 to January 2013 \& the results compared to the final diagnosis which was determined by histopathological \& surgical findings

Results: Most sonographyically indeterminate adnexal masses result from common benign condition. Benign conditions account for $87.6 \%$, while malignant condition account for $12.4 \%$. Endometriosis was the commonest cause constitute $(22.4 \%)$, followed by mature cystic teratoma , and pedunculated fibroid $(18 \%)$ and (15.7\%) respectively. Excellent agreement was noted between MRI and final diagnosis for determining the origin and tissue characteristics which are $98 \%$ and $91 \%$ respectively.

Conclusion: Sonographically indeterminate adnexal masses of uncertain origin and solid or complex content will benefit from further evaluation with MRI, which is highly accurate for identifying the origin of the mass and characterizing its tissue contents playing an important role in planning the way of management.
\end{abstract}

Key words: adnexal masses, ultrasound, magnetic resonance imaging.

\section{Introduction:}

Ultrasonography (US) continues to be the primary imaging modality used to identify and characterize adnexal masses (1). Certain conditions that hinder accurate ultrasound examination, such as obesity, may be indications for magnetic resonance (MR) imaging, for the assessment of complex and indeterminate ovarian masses. (2)

Ultrasound has many advantages: it is relatively inexpensive, provides multiplanar views, is widely available and lacks ionising radiation. Its portability allows use in virtually any setting. Computed tomography (CT) is the most commonly used primary imaging study for evaluating the extent of gynaecological malignancies and for detecting persistent and recurrent disease although there is increasing use of MR imaging (3).

MR imaging, because of its excellent capacity to differentiate tissue types, is particularly useful in making an imaging diagnosis of pelvic disease (4). Patient preparation is minimal.

\footnotetext{
*x-ray institute, Medical City.

**corresponding Auther: Dept. of radiology, Baghdad Teaching Hospital, Medical City.

athrreadnan@gmial.com

***Dept. of Gynecology \& Obstetrics, Baghdad Teaching Hospital, Medical City.
}

There are no need for fasting \& full bladder (5).

The basic series of MR imaging should comprise a pair of T1 -weighted and T2 - weighted sequences T2-weighted sagittal sequence of the pelvis to assess the uterus and the position of adnexal mass and a covering the indeterminate adnexal mass in an orthogonal plane with similar section thickness to allow precise comparison of its tissue characteristics, anatomical location \& organ of origin. Fat -suppressed T1weighted sequence is best reserved for problem solving of T1-weighted bright masses. The Fat-suppressed T1-weighted sequence should be performed in the same plane as the T1weighted sequence and within similar parameters to allow direct comparison (5).

The use of intravenous contrast material (gadolinium chelates , $0.1 \mathrm{mmol} / \mathrm{kg}$ ) is essential to differentiate malignant from benign adnexal masses. Dynamic multiphase contrast - enhanced pelvic imaging can be performed with fat -suppressed 3dimensional T1- weighted gradient -recalled - echo imaging. (6)

To determine the site of origin of indeterminate adnexal mass it is important to identify both ovaries, presuming there has not been prior resection. The process of assessment of the sonographically indeterminate adnexal mass is divided into 
two parts: evaluation of the predominant signal characteristic and morphology of the mass. (5)

The purpose of this study was to assess sensitivity, specificity and accuracy of MRI to characterize sonographically indeterminate adnexal masses.

\section{Patients and Methods}

A prospective study performed in X-ray institute in Medical City Complex in Baghdad from October 2011 to January 2013.

Inclusion criteria include; suboptimal ultrasound image quality, inability to determine the origin of the mass (e.g. very large mass), lack of tissue specificity on ultrasound. Exclusion criteria include: correctly diagnosed adnexal masses on ultrasound, when there is contraindication for MRI \& during pregnancy.

After obtaining ethical approval, 89 patients with pelvic masses with an age between (12 - 64) years were included in this study. All patients underwent transabdominal US. Transvaginal US was done for most patients except virgins and patients who refused it. The equipment used was PHILIPS IU 22 \{convex probe frequency (5-2MHZ), endovaginal probe frequency $(8-4 \mathrm{MHZ})\}$

All patients underwent pelvic MR imaging using Siemens AVANTO MRI unit 1.5 Tesla with pelvic phased array coils. No preparation was required.

The following sequences were performed; T2 -weighted sagittal, axial \& coronal images. T1-weighted transverse images (with and without fat-suppression). Then intravenous gadolinium chelates (with a dose of $0.1 \mathrm{mmol} / \mathrm{kg}$ ) was injected. T1 volumetric breath -hold examination with fat -suppression have been done to evaluate the enhancement of the lesion.

The MRI images were scrutinized for unilaterality, location, size, configuration, signal intensity, pattern of enhancement, extension to surrounding structures, the presence of ascites or lymphadenopathy.

The results were compared to the final diagnosis which was determined by histopathological and surgical findings.

\section{Results}

There were 89 females enrolled in this study, with an age between (12 - 64) years.

Site: Right ovary was more common site of lesion compared to other sites, it was found in $29(32.5 \%)$ of cases (as shown in table 1)
Table (1) Distribution of sites of lesion among study population

\begin{tabular}{ccc}
\hline Site of lesion & Frequency & Percent \\
\hline Right ovary & 29 & $32.5 \%$ \\
\hline Left ovary & 19 & $21.3 \%$ \\
\hline Pedunculated fibroids & 14 & $15.7 \%$ \\
\hline Bilateral ovaries & 9 & $10.1 \%$ \\
\hline Tubes & 6 & $6.7 \%$ \\
\hline Tubo-ovarian & 6 & $6.7 \%$ \\
\hline Peritoneal & 4 & $4.5 \%$ \\
\hline Mullarian & 2 & $2.2 \%$ \\
\hline Total & 89 & 100.0 \\
\hline
\end{tabular}

In this study, the bridging vascular sign found in 13 from 14 cases of pedunculated fibroids, while folded appearance $\mathrm{C}$ or $\mathrm{S}$ shape is clearly seen in 11 from 12 cases of tubal pathology and peritoneal inclusion cyst (recognized by the shape of peritoneal space and by presence of the ovary inside it) seen in two case in this study.

Size: all the malignant lesions detected of size larger than 4 $\mathrm{cm}$, while many benign cystic lesions are larger than $4 \mathrm{~cm}$

T1 bright signal intensity: Blood content lesions were more common \& were found in 33 from $51(64.7 \%)$ of cases (as shown in table 2).

Table (2) distribution of masses with T1 bright signal intensity

\begin{tabular}{|c|c|c|c|c|}
\hline $\begin{array}{l}\text { Mass with } \\
\text { TI bright } \\
\text { single }\end{array}$ & percent & pathology & $\begin{array}{l}\text { Number } \\
\text { of patients }\end{array}$ & percent \\
\hline \multirow{5}{*}{$\begin{array}{l}\text { Blood } \\
\text { contents }\end{array}$} & \multirow{5}{*}{$64.7 \%$} & Endometriomas & 20 & $39.2 \%$ \\
\hline & & Hemorrhagic cyst & 8 & $15.6 \%$ \\
\hline & & Ectopic pregnancy & 2 & $3.9 \%$ \\
\hline & & $\begin{array}{l}\text { Mullerian system } \\
\text { anomalies with atresia of } \\
\text { RT mullerian system and } \\
\text { RT hematometrocolpos }\end{array}$ & 1 & $1.9 \%$ \\
\hline & & $\begin{array}{l}\text { Endometriod and } \\
\text { cystadenocarcinoma }\end{array}$ & 2 & $3.9 \%$ \\
\hline Fat contents & $31.3 \%$ & Mature cystic teratoma & 16 & $31.3 \%$ \\
\hline \multirow[t]{2}{*}{$\begin{array}{l}\text { Mucin } \\
\text { contents }\end{array}$} & $3.9 \%$ & $\begin{array}{l}\text { Mucinous cystadeno- } \\
\text { carcinoma }\end{array}$ & 2 & $3.9 \%$ \\
\hline & $100 \%$ & Total & 51 & $100 \%$ \\
\hline
\end{tabular}


The distribution of lesions of specific tissue characteristics VS particular signal intensity is shown in table 3 below Table 3

\begin{tabular}{|c|c|c|c|c|}
\hline Particular signal intensity & $\begin{array}{l}\text { Specific tissue } \\
\text { characteristic }\end{array}$ & $\begin{array}{l}\text { No. of patients with this } \\
\text { specific signal pattern }\end{array}$ & $\begin{array}{l}\text { Total number } \\
\text { of patients }\end{array}$ & percent \\
\hline Bright lesions on $\mathrm{T} 1$ and $\mathrm{T} 2$ & Hemorrhagic lesions & 34 & 34 & $100 \%$ \\
\hline Bright -dark fluid level on T2 WI (shading ) & $\begin{array}{l}\text { Blood products in } \\
\text { endometriosis }\end{array}$ & 20 & 20 & $100 \%$ \\
\hline $\begin{array}{l}\text { Bright signal on T1 suppressed on fat } \\
\text { suppression }\end{array}$ & Fat content in tumours & 16 & 16 & $100 \%$ \\
\hline Solid mass of Intermediate to Dark signal on T2 & $\begin{array}{c}\text { Lieomyomatous tissue } \\
\text { of fibroid }\end{array}$ & 13 & 14 & $92 \%$ \\
\hline $\begin{array}{l}\text { Alternating bright and dark signal in both } \mathrm{T} 1 \\
\text { and } \mathrm{T} 2 \text { in locules of multilocular cysts }\end{array}$ & $\begin{array}{l}\text { Mucin content in } \\
\text { tumors }\end{array}$ & 3 & 4 & $75 \%$ \\
\hline $\begin{array}{l}\text { multilobulated solid T2 hyperintense mass with } \\
\text { prominent hypointense fibrovascular septae }\end{array}$ & Dysgerminoma & 1 & 1 & $100 \%$ \\
\hline
\end{tabular}

Enhancement pattern: can differentiate between cystic \& solid lesions as shown in table 4.

Table (4) Enhancement patterns

\begin{tabular}{|c|c|c|c|c|c|}
\hline $\begin{array}{l}\text { Consistency of the } \\
\text { lesions }\end{array}$ & Patteren of enhancement & pathology & $\begin{array}{l}\text { No. of } \\
\text { patients }\end{array}$ & $\begin{array}{c}\text { Thick wall> } \\
\text { 3mm }\end{array}$ & Total \\
\hline \multirow{14}{*}{$\begin{array}{l}\text { Cystic or complex } \\
\text { cystic } \\
\text { Or cystic solid } \\
\text { component }\end{array}$} & \multirow{6}{*}{$\begin{array}{l}\text { Peripheral enhancement } \\
\text { without internal enhancement }\end{array}$} & PID & 3 & 3 & \multirow{6}{*}{$\begin{array}{l}\text { All are } \\
\text { benign } \\
\text { conditions }\end{array}$} \\
\hline & & Ectopic pregnancy & 2 & 2 & \\
\hline & & hydrosalpiinx & 1 & $\mathbf{0}$ & \\
\hline & & Cystic degeneration of fibroid & 1 & 1 & \\
\hline & & \multirow{2}{*}{ Total } & \multirow{2}{*}{7} & 6 & \\
\hline & & & & 7 & \\
\hline & \multirow{3}{*}{$\begin{array}{l}\text { Internal enhancement [thin(3 } \\
\text { mm ) regular septal] } \\
\text { Without nodular enhancement }\end{array}$} & Ser. Cyst. Adenoma & 3 & & \multirow{3}{*}{$\begin{array}{l}\text { All are } \\
\text { benign } \\
\text { conditions }\end{array}$} \\
\hline & & Mucinous .cyst.adenoma & 1 & & \\
\hline & & Total & 4 & & \\
\hline & \multirow{5}{*}{$\begin{array}{l}\text { Internal enhancement (thick or } \\
\text { irregular septal and or mural } \\
\text { vegetation enhancement) }\end{array}$} & Serous cystadenocarcinoma & 6 & $60 \%$ & \multirow{3}{*}{$\begin{array}{l}\text { So } 90 \% \text { in } \\
\text { malignant } \\
\text { condition }\end{array}$} \\
\hline & & Mucinous cystadenocarcnoma & 2 & $20 \%$ & \\
\hline & & Endometroid ca. & 1 & $10 \%$ & \\
\hline & & Acute PID & 1 & $10 \%$ & \multirow{2}{*}{$10 \%$ benign } \\
\hline & & Total & 10 & $100 \%$ & \\
\hline \multirow{5}{*}{ Solid masses } & $\begin{array}{c}\text { Solid without significant } \\
\text { enhancement }\end{array}$ & Pedenculated Fibroids & 9 & & Benign \\
\hline & \multirow{3}{*}{$\begin{array}{c}\text { Solid with significant } \\
\text { heterogeneous enhancement }\end{array}$} & Dysgerminoma & 1 & & \multirow{3}{*}{ Malignant } \\
\hline & & Metasteses & 1 & & \\
\hline & & 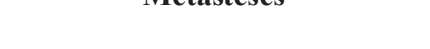 & 2 & & \\
\hline & $\begin{array}{c}\text { Solid with significant } \\
\text { homogenous enhancement }\end{array}$ & Pedenculated fibroids & 4 & & Benign \\
\hline
\end{tabular}

Final diagnosis: was determined by histopathological examination in 85 cases \& by surgical findings in 4 cases.

On basis of MRI, 15 lesions were identified as malignant and 74 lesions identified as benign.

On histopathological basis, 11 were malignant and 78 were benign, by comparison of these finding, MRI agreed with histopathological examination in 10 of 11 malignant, and 73 of 78 benign as shown in table (5). 
Table (5) Validity of MRI in determination of benignity vs malignancy

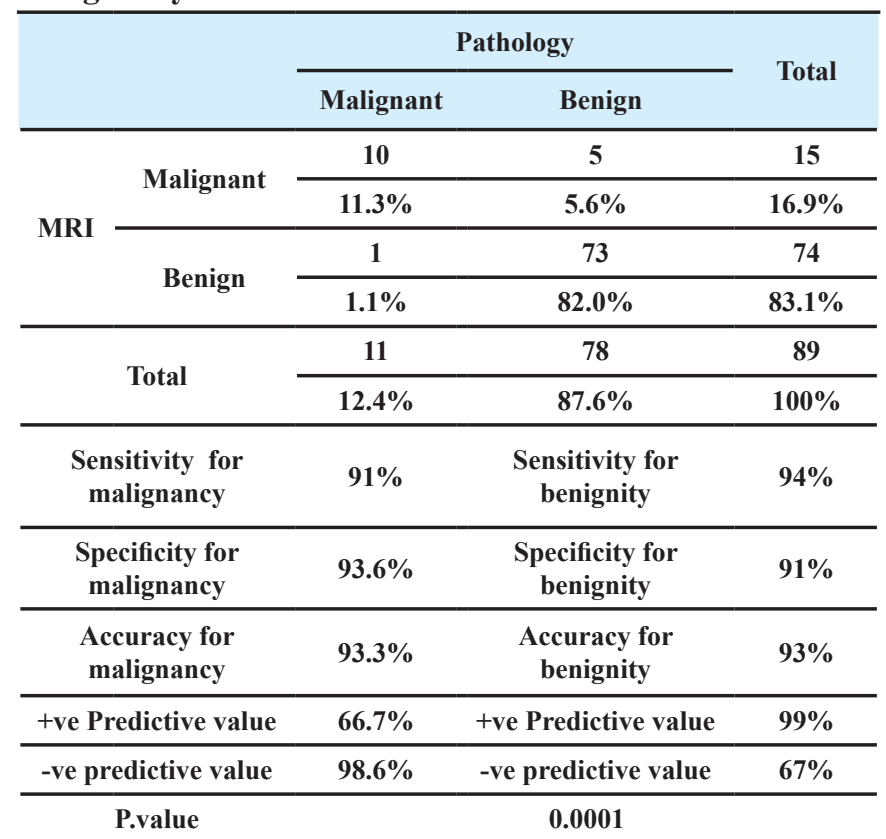

Regarding the location of lesions, MRI correctly identifies the location in (97.8\%) of cases. On the other hand MRI correctly identifies the tissue characteristics in $91 \%$

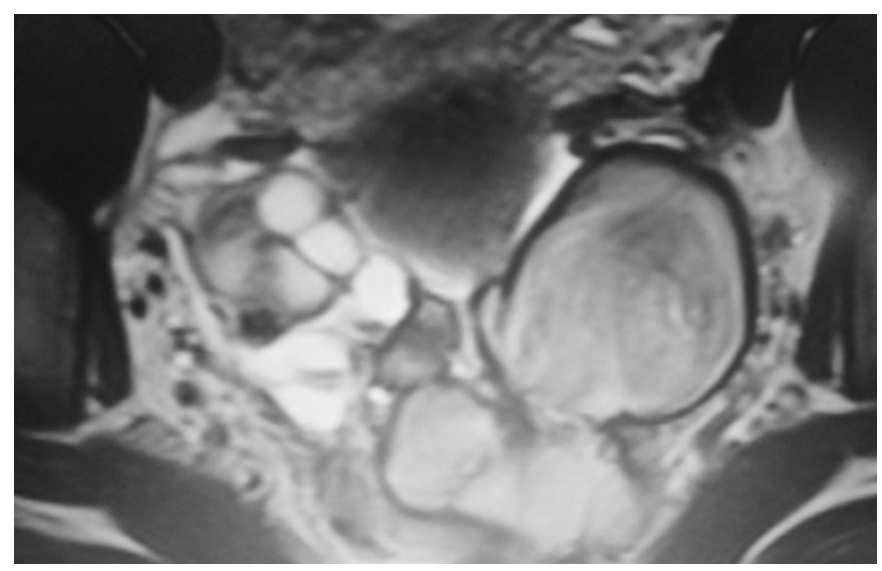

Figure-1 show axial T2 MRI image of tubo-ovarian endometriosis

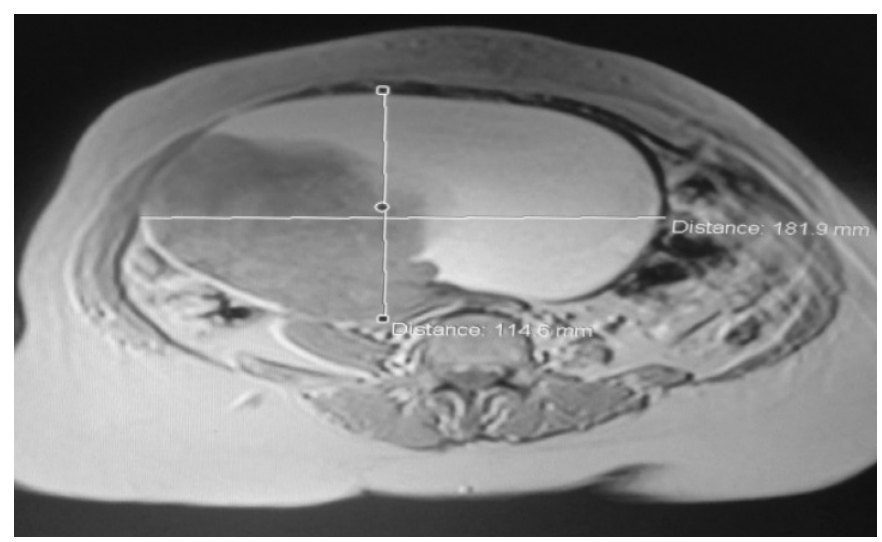

Figure-2 show axial T1 MRI image of hemorrhagic complex mass (cystadenocarcinoma)

\section{Discussion}

Determining the origin of the lesion: In this study, we depend on visualization of its attachment to ovaries or its separation from ovaries, all extraovarian lesions were correctly determined as being extraovarian lesion except one case which is diagnosed finally as (degenerated fibroid) was misdiagnosed on MRI as being ovarian neoplasm. The non-visualization of separate ovaries in postmenopausal women is contributed to the diagnostic dilemma.

In this study, we correctly diagnose 13 from 14 pedunculated fibroids which is consistent with results of studies performed by Scoutt et al \& Kim et al $[7,8]$

In all cases of pedunculated fibroids, there was positive bridging vessels sign, these results agree with a study performed by Adusumilli S et al [9].

In this study, the folded appearance was clear in 11 of 12 tubal lesions while 1 tubal lesion appear as rounded irregular non enhancing thick walled cyst with dark rim on T2 sequences which was chronic pregnancy misdiagnosed as broad ligament fibroid on MRI.

According to these findings there was excellent agreement between MRI and the final diagnosis for determining the origin of the lesion (0.97) as shown in table (3) which is higher than the results of Adusumilli et-al at 2006 in which the result was $(0.93)$

In comparison with a study of Adusumilli et-al at 2006, in our study most masses were ovarian (constituting $64 \%$ of cases), higher than the Adusumilli study which was (52\%), while uterine lesions constitute $17.9 \%$ which was lesser than seen in Adusumilli study which was $21 \%$ and lastly extraovarian or extrauterine also represent $12.1 \%$ which is nearly similar to Adusumilli study as $13.4 \%$.

Also there is tubo-ovarian lesions found in 6 cases $(6.7 \%)$ which are not seen in Adusumilli study. In three lesions the final diagnosis is hydrosalpinx (3.4\%) more frequent than Adusumilli study in which hydrosalpinx $1 \%$ because of differences in study sample.

Acute pelvic inflammatory disease (PID) including TB was the cause in four lesions and hydatid cyst was the cause in two cases. In Adusumilli study, PID and hydatid cyst were not found.

In this study, Müllerian anomalies were seen in two cases (one was complex RT adnexal mass on US \& the other was unicornuate uterus with rudimentary horn on RT side diagnosed by MRI) and peritoneal inclusion cysts constitute $2.2 \%$ for each, which is nearly similar to results in a study by Adusumilli et-al at 2006 which was (3.1\%) for each.

These differences in results attributed to differences in study sample.

The validity of MRI to determine the specific tissue contents: $\mathrm{T} 1$ bright masses are seen in two categories (either hemorrhagic masses or fat containing masses). 
In this study, MRI was excellent in characterizing 20 cases as endometriosis depending on the shading (bright - dark fluidfluid) seen in endometriosis which is consistent with results of studies done by Johna et al \& Outwater et al $[5,10]$.

In this study, MRI was excellent in characterizing 32 lesions as benign hemorrhagic masses (endometriosis, hemorrhagic cysts, ectopic pregnancy and atresia of RT Mullerian system). In this study, 16 lesions were mature cystic teratoma that could not be recognized at US.

These two categories of lesions were relatively more frequent in our study when compared with Adusumilli et-al at 2006 (9).

This difference is most likely attributed to age factor as our study in younger population.

In this study, pedunculated fibroids constitute (15.7\%) in which lieomyomatous tissue and fibrous tissue correctly characterized in $92 \%$ of pedunculated fibroids depending on special signal characteristics which agree results of Johna et al. [5]

Pedunculated fibroids were slightly lesser than what was reported in study done by Adusumilli et-al at 2006 in which the result was $(17.8 \%)$

Mucinous tumors shows particular signal intensity of an alternating bright and dark signal in $\mathrm{T} 1$ and $\mathrm{T} 2$ sequences in $75 \%$ of cases which contain mucin, this finding is agreed with results of Johna et al \& Tanaka et al $[5,11]$.

In this study, mucinous tumor constitute $3.3 \%$ of all cases while Adusumilli et al at 2006 did not report mucinous tumors. (9)

In this study, one case was dysgerminoma with characteristic imaging findings (multilobulated solid T2 hyperintense mass with prominent hypointense fibrovascular septae), this result is consistent with results of Imaoka [12] , but was not reported in Adusumilli et-al at 2006. (9)

The younger age was the cause for these differences in findings because dysgerminoma is the most common malignant tumor among children and young adult [12].

MRI correctly determined specific tissue characteristics such as the presence of fat, blood products or mucin in $91 \%$ of cases which is the exactly the same percent reported in Adusumilli et-al at 2006. (9)

Validity of MRI to in determination of benignity vs malignancy:

Mass size larger than $4 \mathrm{~cm}$ is one of the primary criteria in characterizing malignant lesions. In this study, all malignant lesions were larger than $4 \mathrm{~cm}$ which is similar to what is mentioned in the literature [3].

But 34 lesions were diagnosed benign after final diagnosis were also larger than $4 \mathrm{~cm}$.

Also the authors depend on the consistency of lesion and pattern of enhancement in which all cysts with peripheral enhancement whether thin or thick was due to benign condition. Although thick wall is a sign of malignancy, it can occur in acute inflammatory conditions, this is agreed with the fact that acute tubo-ovarian masses may produce very complex masses with thick wall and pseudosolid areas. These enhance intensely and can mimic malignancy. [13]

In this study, internal enhancement of thin and regular septae seen only benign conditions which is similar to results of a study done by Outwater et al [10] .

In this study, internal enhancement of thick or irregular septal and or mural vegetation enhancement seen in $90 \%$ of malignant cases and in $10 \%$ of benign cases, those findings agreed with results of a study done by Johna et al [5].

The enhancement of a solid mass also can help in characterization of masses. In this study, solid mass without significant enhancement was diagnosed benign, while solid masses with significant heterogeneous enhancement was diagnosed malignant and solid masses with significant homogenous enhancement was diagnosed benign, all these findings were consistent with results of a study by Johna et al [5].

In this study, all non enhancing lesions were benign except one malignant case which is mucinous cystadenocarcinoma.

In this study, 11 cases were proved to be malignant by histopathology, MRI correctly diagnosed 10 cases as malignant. One case was mucinous cystaenocarcinoma \& MRI correctly characterize it as mucinous tumor but absence of significant enhancement, papillary projection or evidence of seeding classified it as probably benign but on histopathology found to be malignant. This may be attributed to the way of contrast injection.

In this study, 5 lesions were erroneously diagnosed as probably malignant (4 were acute PID and one was degenerated fibroid appearing as ovarian neoplasm in postmenapausel female with atrophied ovary).

In this study, MRI showed high sensitivity (91\%), high specificity (93.6\%) and high accuracy (93.3\%) for characterizing malignant lesions which was slightly lesser than what was reported by Adusumilli et al at 2006 which was $100 \%(9)$, this difference can be attributed to the percentage of malignant lesion in this study (slightly more than their study). The specificity of MRI for benign lesions was high (91\%) which is nearly similar to what was reported by Adusumilli et al at $2006(90 \%)$.

\section{Conclusion:}

Sonographically vague adnexal masses will benefit from additional assessment with pelvic MRI which is highly accurate for identifying the origin of the mass, characterizing its tissue contents and planning the way of management.

MRI allows identification of blood products within hemorrhagic masses or fat in fat containing masses that may mimic solid tumor at US.

Contrast -enhanced T1-wieghted sequence depicts features of 
malignancy such as enhancing mural nodules and/or enhancing solid areas with or without necrosis

\section{Author contribution:}

Dr. Salam M. Joori, Study design, interpretation of data, acquisition of clinical data \& critical revision.

Dr. Atheer Adnan Fadhil: Study design, drafting of manuscript $\&$ critical revision.

Dr. Wassen M. Abdullateef: Collection \& acquisition of clinical \& radiological data, drafting of manuscript.

Dr. Maysoon M. Jabir: Collection, acquisition \& interpretation of clinical data.

\section{References}

1. American College of Radiology. ACR Appropriateness Criteria 2008: clinically suspected adnexal masses. American College of Radiology Web site. Available at (http:// www.acr.org/SecondaryMainMenuCategories/quality_ safety/app_criteria/pdf/ExpertPanelonWomensImaging/ SuspectedAdnexalMassesDoc11.aspx. Accessed November 9, 2009.

2. Isabelle Thomassin-Naggara, Emilie Aubert, Andrea Rockall, Aurélie Jalaguier-Coudray, Roman Rouzier, Emile Daraï, Marc Bazot. Adnexal Masses: Development and Preliminary Validation of an MR Imaging Scoring System. Radiology, 2013, Vol. 267: 432-443 (IVSL)

3. Sala E., Freeman S., Ascher S., Hricak H. : Gynecological cancer. In: A. Adam , A. K. Dixon, J. H. Gillard \& C. M. Schaefer-Prokop eds. Grainger \& Allison's diagnostic radiology, $6^{\text {th }}$ edition, volume 2 . London, Churchil Livingstone, 2015: p:957-971

4. Brant W. E.: Genital tract - CT, $M R$, and radiographic anatomy. In: W. E. Brant \& C. A. Helms eds. Fundamentals of diagnostic radiology, $4^{\text {th }}$ edition, volume 3. Philadelphia, Lippincott Williams \& Wilkins, 2012: p:838-856.

5. Johna. $S$,Sur G, MR imaging of the sonographically indeterminate adnexal mass. Radiology, 2010, vol. 256(3):67578

6. Rajkotia K. , Veeramani M., Macura K. J., Magnetic Resonance Imaging of Adnexal masses. Top Magn Reson Imaging $2006 ; 17(6): 383-94$.

7. Scoutt LM, McCarthy SM, Lange R, Bourque A, Schwartz PE. MR evaluation of clinically suspected adnexal masses. $J$ Comput Assist Tomogr 1994; 18:609-618.

8. Kim JC, Kim SS, Park JY. "Bridging vascular sign" in the MR diagnosis of exophytic uterine leiomyoma. J Comput Assist Tomogr 2000; 24:57-60.

9. Adusumilli S, Hussain HK, Caoili EM, et al . MRI of sonographically indeterminate adnexal mass AJR Am J Roentgenol 2006;187(3):732-740. (IVSL).

10. Outwater EK, Dunton CJ. Imaging of the ovary and adnexa: clinical issues and applications of MR imaging Radiology 1995; 194:1-18.
11. Tanaka YO, Nishida M, Kurosaki Y, Itai Y, Tsunoda H, Kubo T. Differential diagnosis of gynaecological "stained glass" tumours on MRI. Br J Radiol 1999 ; 72 ( 856 ): 414 - 420.

12. Imaoka I, Wada A, Kaji Y, et al. Developing an MR imaging strategy for diagnosis of ovarian masses. Radiographics 2006;26:1431-1448.

13. Kim SH, Kim SH, Yang DM, Kim KA. Unusual causes of tubo-ovarian abscess: $C T$ and MR imaging findings. RadioGraphics 2004; 24 (6): 1575 - 1589. 